\title{
Synthesis and Chromatographic Separation of the Stereoisomers of Furnidipine
}

\author{
Ramón Alajarin, ${ }^{\mathbf{a}}$ Julio Alvarez-Builla, ${ }^{\mathrm{a}^{*}}$ Juan J. Vaquero, ${ }^{\mathrm{a}}$ Carlos Sunkel, ${ }^{\mathrm{b}}$ Miguel Fau de \\ Casa-Juana, ${ }^{\text {b }}$ Peter R. Statkow, ${ }^{\text {b }}$ and Julia Sanz-Aparicio ${ }^{c}$
}

(a) Departamento de Química Organica, Universidad de Alcalá, Alcalá de Henares. Madrid. Spain

(b) Cermol S.A. 62 Rue de Lyon. Geneve. Switzerland

(c) Departamento de Rayos X. Instituto Rocasolano, CSIC, 28006-Madrid. Spain

(Received in UK 22 January 1993)

Key words: Furnidipine; synthesis; chiral HPLC; four stereoisomers; separation

\begin{abstract}
The four stereoisomers of methyl tetrahydrofuran-2-ylmethyl 2,6-dimethyl-4-(o-nitrophenyl)-1,4-dihydropyridine-3,5-dicarboxilate (furnidipine), have been synthesized and separated by chiral chromatography using D-phenylglycine as chiral stationary phase. Enantiomeric purity of stereoisomers is determined by HPLC-CSP technique and configurations deduced via X-ray crystallography.
\end{abstract}

The 4-aryl-1,4-dihydropyridines ${ }^{1}$ first prepared by Hantzsch ${ }^{2}$ have attracted substantial attention since the discovery of their calcium antagonists properties. ${ }^{3}$ Their subsequent therapeutical applications has led to an enormous effort being devoted to the clinical development of new derivatives. The symmetrically substituted dimethyl 2,6-dimethyl-4-(o-nitrophenyl)-1,4-dihydropyridine-3,5-dicarboxylate (Nifedipine) was the first 1,4-dihydropyridine used clinically against angina pectoris and hypertension. ${ }^{4}$ More recent pharmacological studies on other members of this class of drugs has shown that the enantiomers of chiral 1,4-dihydropyridines such as nimodipine and nicardipine exhibited not only activities quantitatively different but also qualitatively. ${ }^{5}$ Moreover, there are even examples in which both enantiomers have the opposite action profile with one of the enantiomers being a calcium antagonist and the other one a calcium agonist. In view of the great importance of chirality to pharmacological activity in these drugs, the separation of enantiomers or the development of stereoselective syntheses is of great interest for obtaining new and more selective molecules with therapeutical applications. ${ }^{6}$

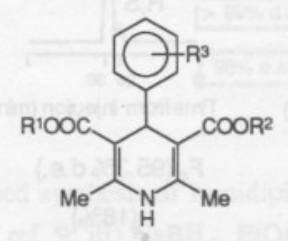

$R^{1}=R^{2}=M e ; R^{3}=2-\mathrm{NO}_{2}$ (Nifedipine)

$\mathrm{R}^{1}=\mathrm{H} \mathrm{Pr} ; \mathrm{R}^{2}=\mathrm{CH}_{2} \mathrm{CH}_{2} \mathrm{OMe} ; \mathrm{P}^{3}=3-\mathrm{NO}_{2}$ (Nimodipine)

$\mathrm{R}^{1}=\mathrm{Me} ; \mathrm{P}^{2}=\mathrm{CH}_{2} \mathrm{CH}_{2} \mathrm{~N}(\mathrm{Me})(\mathrm{Bn}) ; \mathrm{R}^{3}=3-\mathrm{NO}_{2}$ (Nicardipine)

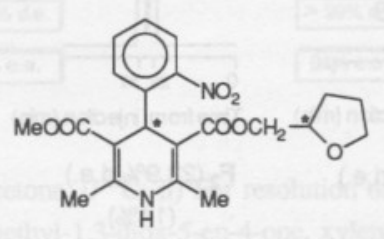

1 (Fumidipine)

\section{Scheme 1}

As result of a screening by Cermol S.A. laboratories of the calcium antagonist activity of numerous 4-aryldihydropyridine-3,5-dicarboxilates we have found that methyl tetrahydrofuran-2-ylmethyl 2,6-dimethyl-4-(o-nitrophenyl)-1,4dihydropyridine-3,5-dicarboxylate 1 (furnidipine), is a new, highly active and specific calcium antagonist. This 
dihydropyridine derivative is also a chiral structure and exists as four stereoisomers, all of them needed in enantiomerically pure form for pharmacological studies directed to determine possible activity differences.

Optically active 1,4-dihydropyridines have been prepared either by chemical or enzymatic resolution of the racemates or by chiral chromatographic separation of the antipodes. ${ }^{7}$ The preparation of pure four stereoisomers of 1 was first attempted by adapting the method reported by Shibanuma and co-workers ${ }^{8}$ with the acid 4 by resolution of 5-methoxycarbonyl-2,6-dimethyl-4-( $o$-nitrophenyl)-1,4-dihydropyridine-3carboxylic acid $\mathbf{3}$ and esterification of the acid with enantiomeric pure tetrahydrofurfuryl alcohol. The process however, failed because the $o$-nitro group facilitates the oxidation of the dihydropyridine moiety, the product being the pyridine derivative isolated under different conditions. A similar process has been described for nifedipine itself and several 2-nitrophenyl derivatives .

The possibility of preparing the enantiomerically pure acid from unsymmetrically substituted 1,4-dihydropyridines obtained by asymmetric synthesis was also considered but

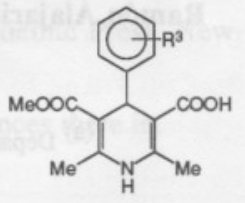

3: $\mathrm{R}^{3}=2-\mathrm{NO}_{2}$ 4: $\mathrm{R}^{3}=3-\mathrm{NO}_{2}$

Scheme 2 discarded since nifedipine analogues bearing 2-nitrophenyl substituents on $\mathrm{C}-4$ have not been prepared in enantiomerically pure form in the two previously reported asymmetric syntheses of chiral dihydropyridines. ${ }^{9.10}$ Therefore, we decided to develop a method based on separation of covalent diastereomers.

The simple synthetic route starts with commercially available racemic tetrahydrofurfuryl alcohol $\mathbf{5}$ which was transformed to the racemic acid with Jones's reagent and the acid resolved following the method described by Belanger and col. ${ }^{11}$ Esterification of the enantiomeric acids gave the esters which were reduced with $\mathrm{NaBH}_{4}$ fumishing (S)- and (R)-tetrahydrofurfuryl alcohols. ${ }^{12,13}$ Further elaboration into diastereomeric furnidipine $1 \mathbf{a}$ and $\mathbf{1 b}$ via a modified Hantzsch synthesis ${ }^{14,15}$ is shown in Scheme 3. In both possible routes $1 \mathbf{a}$ and $\mathbf{1 b}$ were obtained as a (50:50) mixture of diastereomers and no diastereomeric excess was detected under different conditions.

The separation of diastereomers was carried out by chiral preparative HPLC using a Pirkle column $(250 \times 30 \mathrm{~mm}$ i.d.) packed with D-phenylglycine. ${ }^{16}$ Samples $(0.5 \mathrm{ml})$ were injected as solutions in the eluent (dichloromethane) at a flow rate of $22 \mathrm{ml} / \mathrm{min}$ and detected by absorbance at $254 \mathrm{~nm}$. In a typical separation a dichloromethane solution of furnidipine 1a ( $\mathrm{c}=80 \mathrm{mg} / \mathrm{ml})$ afforded four fractions $\left(\mathrm{F}_{1}-\mathrm{F}_{4}\right.$ in Figure 1) which after being rechromatographed (twice for $\mathrm{F}_{3}$ ) gave pure diastereomers $(>99 \%$ d.e.).

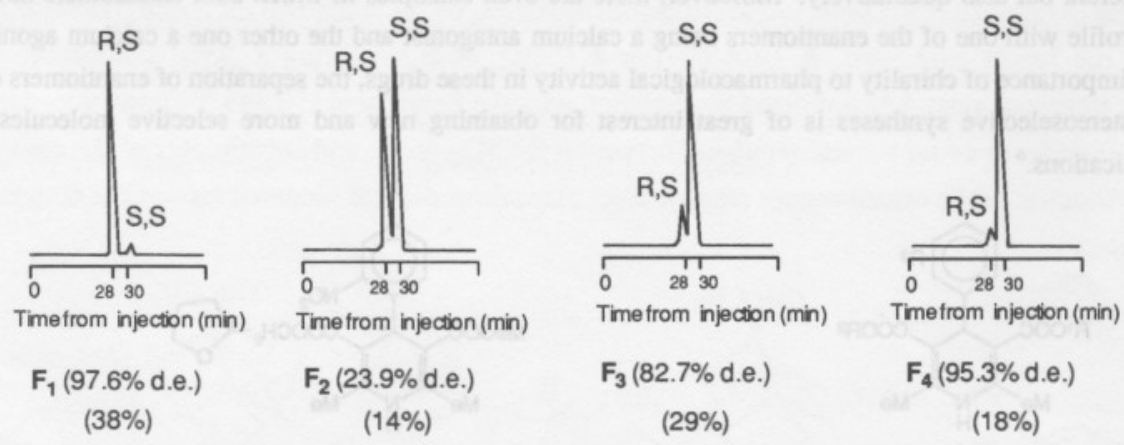

Figure 1. Analytical chromatogram from the chiral HPLC of a mixture of R,S-1 and $S, S-1$ on a Pirkle column $(250 \times 4.6 \mathrm{~mm}$ i.d.). Samples $(20 \mu$, c $0.1 \mathrm{mg} / \mathrm{ml})$ were injected in dichlorometane as a flow rate of $1.5 \mathrm{~m} / \mathrm{min}$ and detécted by absorbance at $335 \mathrm{~nm}$.

The enantiomeric purity of the four stereoisomers of 1 (Scheme 3) was also determined by HPLC-CSP by using an $\alpha_{1}$-acid glycoprotein column ${ }^{17}$ (100 x $4.6 \mathrm{~mm}$ i.d.) with $\mathrm{H}_{2} \mathrm{O} / \mathrm{i}-\mathrm{PrOH}(9: 1)$ as eluent and a flow rate of $0.2 \mathrm{ml} / \mathrm{min}$. A $20 \mu \mathrm{l}$ injected sample $(\mathrm{c}=0.1 \mathrm{mg} / \mathrm{ml})$ detected by absorbance at $335 \mathrm{~nm}$ gave retention times between 24 and $32 \mathrm{~min}$ for the stereoisomers. 


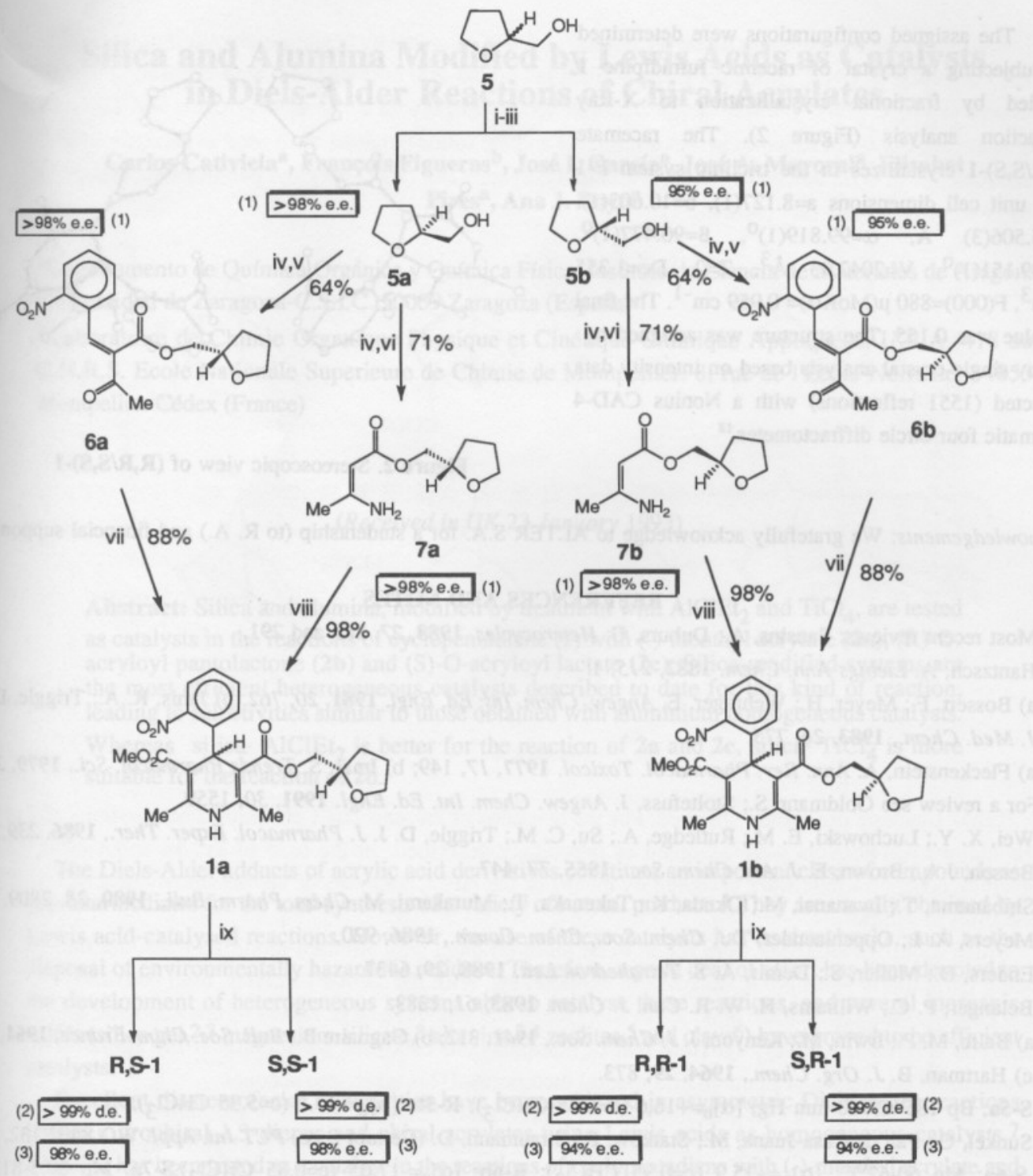

Scheme 3. Simplified synthesis of furnidipine. i)Jones's reagent, acetone, $0^{\circ} \mathrm{C}$; ii) For resolution of the acid and ester formation see ref. 9; iii) $\mathrm{NaBH}_{4}$, EtOH, reflux; iv) 2,2,6-Trimethyl-1,3-diox-5-en-4-one, xylene, reflux;

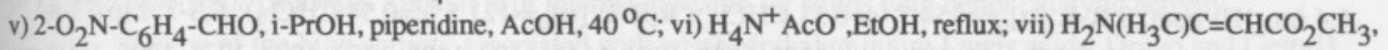

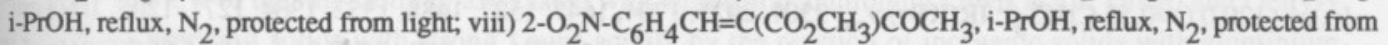
light; ix) Chiral chromatographic separation.

(1) Determined by ${ }^{1} \mathrm{H}-\mathrm{NMR}$ analysis with Eu(hfc) 3 ; ${ }^{(2)}$ Determined by HPLC-CSP (Pirkle column, see text);

(3) Determined by HPLC-CSP ( $\alpha_{1}$-acid glycoprotein column, see text). 
The assigned configurations were determined by subjecting a crystal of racemic furnidipine 1 purified by fractional crystallization to X-Ray diffraction analysis (Figure 2). The racemate $(\mathbf{R}, \mathbf{R} / \mathbf{S}, \mathbf{S})-1$ crystallizes in the triclinic system P-1 with unit cell dimensions $a=8.127(1), b=10.603(1)$, $\mathrm{c}=25.506(3) \quad \AA, \quad \alpha=99.819(1)^{\circ}, \quad B=90.477(1)^{\circ}$, $\gamma=109.151(1)^{0}, \quad V=2042.93 \quad \AA^{3}, \quad Z=2, \quad D c=1.355$ $\mathrm{g} / \mathrm{cm}^{3}, \mathrm{~F}(000)=880 \mu(\mathrm{MoK} \alpha)=0.959 \mathrm{~cm}^{-1}$. The final $R$ value was 0.155 . The structure was assigned by $\mathrm{X}$-Ray single-crystal analysis based on intensity data collected (1551 reflections) with a Nonius CAD-4 automatic four-circle diffractometer. ${ }^{18}$

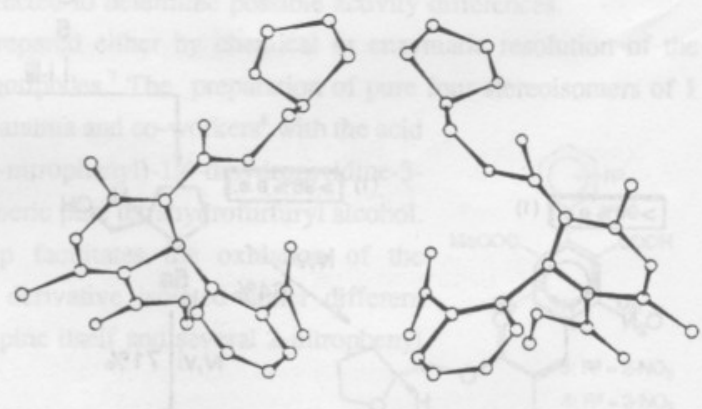

Figure 2. Stereoscopic view of $(\mathbf{R}, \mathbf{R} / \mathbf{S}, \mathbf{S})-1$

Acknowledgements: We gratefully acknowledge to ALTER S.A. for a studentship (to R. A.) and financial support

\section{REFERENCES AND NOTES}

1. Most recent reviews: Sausins, A.; Duburs, G. Heterocycles, 1988, 27, 269 and 291.

2. Hantzsch, A. Liebigs Ann. Chem. 1882, 215, 1.

3. a) Bossert, F.; Meyer, H.; Wehinger, E. Angew. Chem. Int. Ed. Engl. 1981, 20, 762. b) Janis, R. A.; Triggle, D. J. J. Med. Chem., 1983, 26, 775.

4. a) Fleckenstein, A. Ann. Rev. Pharmacol. Toxicol. 1977, 17, 149; b) Imai, S. Trends Pharmacol. Sci., 1979, 2, 81

5. For a review see Goldmann S.; Stoltefuss, J. Angew. Chem. Int. Ed. Engl. 1991, 30, 1559.

6. Wei, X. Y.; Luchowski, E. M.; Rutledge, A.; Su, C. M.; Triggle, D. J. J. Pharmacol. Exper. Ther., 1986, $239,144$.

7. Berson, J.A.; Brown, E. J. Am. Chem. Soc., 1955, 77, 447.

8. Shibanuma, T.; Iwananai, M.; Okuda, K.; Takenaka, T.; Murakami, M. Chem. Pharm. Bull., 1980, 28, 2809.

9. Meyers, A. I.; Oppenlaender, T J. Chem. Soc., Chem. Comm., 1986, 920.

10. Enders, D.; Müller, S.; Demir, A. S. Tetrahedron Lett. 1988, 29, 6437.

11. Belanger, P. C.; Williams, H. W. R. Can. J. Chem. 1983, 61, 1383.

12. a) Balfe, M. P.; Irwin, M.; Kenyon, J. J. Chem. Soc., 1941, 312; b) Gagnaire B.; Bull. Soc. Chim. France, 1961, 312; c) Hartman, B. J. Org. Chem., 1964, 29, 873.

13. S-5a: Bp $185^{\circ} \mathrm{C} / 760 \mathrm{~mm} \mathrm{Hg} ;[\alpha]_{D}=+16,6\left(\mathrm{c}=5.35 \mathrm{CHCl}_{3}\right)$; R-5b: $[\alpha]_{D}=-15.8\left(\mathrm{c}=5.35 \mathrm{CHCl}_{3}\right)$.

14. Sunkel, C.; Fau de Casa-Juana, M.; Statkow, P.; Straumann, D. (Cermol S.A.) PCT Int. Appl. WO 8402,132, 1984

15. S-6a: Mp $60-62^{\circ} \mathrm{C} ;[\alpha]_{D}=+15.9\left(\mathrm{c}=0.95 \mathrm{CHCl}_{3}\right)$; R-6b: $[\alpha]_{\mathrm{D}}=-17.05\left(\mathrm{c}=0.85 \mathrm{CHCl}_{3}\right) \cdot \mathrm{S}-7 \mathrm{a}: \mathrm{Mp} 80.5-81.5^{\circ} \mathrm{C}$; $[\alpha]_{D}=+31.7\left(\mathrm{c}=1.11 \mathrm{CHCl}_{3}\right) ; \mathbf{R}-7 \mathbf{b}:[\alpha]_{D}=-27.3\left(\mathrm{c}=1.22 \mathrm{CHCl}_{3}\right) ; \mathbf{R}, \mathrm{S}-1: \mathrm{Mp} \mathrm{53-55}{ }^{\circ} \mathrm{C} ;[\alpha]_{D}=-154.3\left(\mathrm{c}=0.49 \mathrm{CHCl}_{3}\right)$; $\operatorname{IR}(\mathrm{KBr}) \mathrm{v}_{\max } 3297,2946,1697,1528,1496,1354,1275,1208,1115 \mathrm{~cm}^{-1} ;{ }^{1} \mathrm{H}-\mathrm{NMR}\left(300 \mathrm{MHz}, \mathrm{CDCl}_{3}\right) \delta 7.8-7.1$ (m, 4H); 6.03 (bs, 1H); 5.75 (s, 1H); 4.2-3.6 (m, 5H);3.54 (s, 3H); 2.31 (s, 3H); 2.99 (s, 3H); 2.0-1.7 (m, 3H); 1.6$1.4(\mathrm{~m}, 1 \mathrm{H})$ ppm. S,R-1: $[\alpha]_{D}=+154.7\left(\mathrm{c}=0.51 \mathrm{CHCl}_{3}\right) ; \mathbf{R}, \mathbf{R}-1:[\alpha]_{D}=-121.5\left(\mathrm{c}=0.54 \mathrm{CHCl}_{3}\right) ; \mathrm{S}, \mathrm{S}-1: \mathrm{Mp} 82-84{ }^{\circ} \mathrm{C}$; $[\alpha]_{D}=+120.0\left(\mathrm{c}=0.52 \mathrm{CHCl}_{3}\right) ; \mathrm{IR}(\mathrm{KBr}) v_{\max } 3301,2925,1704,1647,1527,1488,1352,1304,1271,1205,1093 \mathrm{~cm}^{-1}$; ${ }^{1} \mathrm{H}-\mathrm{NMR}\left(300 \mathrm{MHz}, \mathrm{CDCl}_{3}\right.$ ) $\delta 7.69$ (dd, $1 \mathrm{H}, \mathrm{J}=8 \mathrm{~Hz}, \mathrm{~J}=1 \mathrm{~Hz}$ ); 7.6-7.4 (m, 2H); 7.3-7.2(m, 1H); 5.99(bs, $\left.1 \mathrm{H}\right) ; 5.77$ $(\mathrm{s}, 1 \mathrm{H}) ; 4.2-3.6(\mathrm{~m}, 5 \mathrm{H}) ; 3.56(\mathrm{~s}, 3 \mathrm{H}) ; 2.33(\mathrm{~s}, 3 \mathrm{H}) ; 2.30(\mathrm{~s}, 3 \mathrm{H}) ; 2.0-1.7(\mathrm{~m}, 3 \mathrm{H}) ; 1.6-1.4(\mathrm{~m}, 1 \mathrm{H}) \mathrm{ppm}$.

16. Covalent Bonded D-Phenylglycine purchased from Hichrom Ltd., U.K.

17. Chiral-AGP purchased from ChromTech, Sweden.

18. Positional and thermal parameters and lists of observed and calculated structure factors can be obtained from authors and have been deposited at the Cambridge Crystallographic Data Centre. 